\title{
A Study on Clinical Profile, Risk Factors, Angiographic Profile and Short-Term Mortality of Acute Coronary Syndrome in Smokers vs Non Smokers
}

\author{
B V Narayana Reddy ${ }^{\circledR 1}$, Hemasundar Korrapati ${ }^{\odot 2}$, Supraja Chegireddy ${ }^{\circledR 3}$ \\ ${ }^{1}$ Assistant Professor, Department of Cardiology, Katuri Medical College \& Hospital, Andhra Pradesh, India, ${ }^{2}$ Assistant Professor, Department of Cardiology, Katuri \\ Medical College \& Hospital, Andhra Pradesh, India, ${ }^{3}$ Assistant Professor, Department of Radio Diagnosis, Katuri Medical College \& Hospital, Andhra Pradesh, India.
}

\section{Abstract}

Background: Smoking has long been positively associated with the development and progression of coronary heart disease. However, longitudinal cohort studies evaluating smoking habits among cardiac patients as well as the role of socio-demographic factors determining such behaviours are scarce and have been focused on primary care practice. Prevalence of acute coronary syndrome in young individuals is increasing progressively. Previous studies have focused on the analysis of risk factors and to some extent coronary angiographic profile in smokers vs non-smokers patients with acute coronary syndrome. The aim of the study is to study the acute coronary syndrome in smokers versus non-smokers and to analyse with respect to baseline characteristics. Subjects and Methods: It was a prospective study conducted at Department of Cardiology, Katuri Medical College \& Hospital Guntur. Results: In the present study, Acute coronary syndrome occurred seven years earlier in smokers compared with non-smokers $(\mathrm{p}<0.05)$ Smokers were frequently male subjects compared with non-smokers $(\mathrm{p}<0.001)$ Smokers had a lower prevalence of Diabetes compared with non-smokers $(\mathrm{p}<0.001)$ Smokers had a higher prevalence of Obesity compared with non-smokers $(\mathrm{p}<0.001)$. Smokers presented with more acute infarctions and less Unstable angina compared with non-smokers $(\mathrm{P}<0.001)$. Conclusion: In the present study, significant differences were observed in coronary risk factor profile between smokers and non-smokers patients with STEMI and NSTEMI/UA. Larger studies will be required to establish specific associations between presentation of acute coronary syndromes and angiographic profiles in smokers.

Keywords: Acute coronary syndrome, Coronary Angiography, Coronary Artery Disease (CAD), Smokers

Corresponding Author: Hemasundar Korrapati, Assistant Professor, Department of Cardiology, Katuri Medical College \& Hospital, Andhra Pradesh, India.

E-mail: Hemasundar_k@yahoo.com

Received: 3 April 2020

Revised: 10 May 2020

Accepted: 18 May 2020

Published: 6 July 2020

\section{Introduction}

Ischemic heart disease is a major public health problem associated with high morbidity and mortality. Acute coronary syndrome is a common presentation of ischemic heart disease. ${ }^{[1]}$ It is also the single largest cause of death in developed countries as well as developing countries. ${ }^{[2]}$ Despite being identified as a major burden on health-care systems, there have been no large prospective cohort studies to define the incidence of coronary artery disease (CAD) among Indians. Therefore, the magnitude of the problem can only be estimated from cross-sectional point prevalence studies. ${ }^{[3]}$ Reports have shown that risk of CAD among Asian Indians is 3-4 times higher than white Americans, 6 times higher than Chinese, and 20 times higher than Japanese counterparts. ${ }^{[4]} \mathrm{A}$ conservative estimate indicates that there could be 30 million
CAD patients in India. If the current trend continues, the burden of CAD in India will surpass other regions of the world by the year $2020 .{ }^{[5]}$

In addition to higher rate, it is also reported that Indian individuals may develop CAD at a very early age. ${ }^{[6]}$ According to an estimate, more than half of death related to cardiovascular disease occurs in patients below the age of 50 years and one-fourth of acute myocardial infarction cases are being reported in patients under the age of 40 years. ${ }^{[6]} \mathrm{It}$ has also been noted that the clinical presentation, risk factor profile, and coronary anatomy of young patients who develop CAD differs to those who develops CAD at an older age (1, 6 , \& 7). Overall, these studies have indicated that patients with early onset of CAD exhibit preponderance of single vessel disease, and dominance of coronary risk factors such 
as hypercholesterolemia, family history of $\mathrm{CAD}$, and cigarette smoking as compared to older patients. However, there have been very limited data on comparison of demographic and angiographic characteristics in smokers stratified according to the type of acute coronary syndrome.

Therefore, we aimed to identify the differences between risk factor profile and coronary angiographic characteristics of smokers and non smokers patients presenting with STelevated myocardial infarction (STEMI), and non-ST-elevated myocardial infarction (NSTEMI), with respect to baseline characteristics.

\section{Subjects and Methods}

\section{Inclusion criteria}

1. Patients with first episode of ACS (Unstable Angina with ECG changes, NSTEMI,STEMI) attending the ICCU, Department of Cardiology, Katuri Medical College, Guntur.

2. Different types of ACS were diagnosed according to ECG criteria and Troponin $T$ positivity.

3. Both Smokers and non Smokers were included in the study group.

4. Smoking history (all forms-tobacco chewing / khaini / beedi / tambaku / cigars.

5. Troponin positivity (qualitative for NSTEMI differentiating from USA with ECG changes.

6. Coronary angiogram was done after 5 days of Heparin theraphy in acute coronary syndrome.

\section{Exclusion criteria}

1. Age $<18 \mathrm{yrs} />80 \mathrm{yr}$.

2. Patients with recurrent episode of ACS and Cardiogenic shock.

3. Patients with Valvular heart diseases/ cardiomyopathies/ pericardial diseases/ conduction diseases other than ischemia.

4. Contradictions' to CAG (pts with serum creatinine $>1.5 \mathrm{mg} / \mathrm{dl}$,lack of consent for CAG) and prior coronary angiogram report.

\section{Unstable Angina Without Ecg Changes}

The various baseline characteristics studied include, age and sex of the patients, presentation of the Acute coronary syndrome(Unstable angina with ECG changes versus acute myocardial infarction \{acute STEMI+acute NSTEMI),presence of traditional risk factors like hypertension, diabetes, smoking history, obesity, family history of CAD in smokers and compared with non smokers.

\section{The following baseline characteristics were studied:}

1. Age and sex of the study group.

2. Risk factors

- Hypertension: $>/=140 / 90 \mathrm{~mm} \mathrm{Hg} /$ on anti hypertensive medication

- Diabetes: fasting plasma glucose $>/=126 \mathrm{mg} / \mathrm{dl}, 2 \mathrm{hr}$ post prandial glucose $>/=200 \mathrm{mg} / \mathrm{dl}$, Symptoms of DM and random plasma glucose concentration $\geq 200 \mathrm{mg} / \mathrm{dl}$, Patients on treatment for diabetes mellitus.

- Smoking: all forms of smoking-calculated Smoking index with pack years, Current or past smokers (those who have quit within the past six months).

- Family history: CAD in first degree male relatives before the age 55 and in a first degree female relative before the age 65 years.

- BMI: The BMI is calculated by dividing the body weight in kilograms by the square of the height in meters. Patients with BMI of 25-29.9 were considered to be overweight and those with BMI $>30.0$ were considered as obese.

\section{Echocardiography:}

All the echocardiograms were done on a IE 133 phillips echocardiography machine. The echocardiography parameters evaluated included:

- Ejection fraction as impaired LV function ( $\mathrm{EF}<50 \%$ or normal (EF>/50\%).

- Coronary angiograms were performed with SIEMENS CATH LAB on all the patients within 5 to 7 days after ACS /Primary PTCA done in the case of eligible patients. Informed consent was taken from all the patients.

\section{Statistical analyses}

Statistical Analysis was done using SPSS software. Mean, median, standard deviation and Chi Squares were calculated wherever applicable. A value of $\mathrm{p}<0.05$ was considered statistically significant.

\section{Results}

\section{Distribution of the study subjects:}

\begin{tabular}{lll}
\hline \multicolumn{2}{l}{ Table 1: Study subjects } \\
\hline Smokers & Non smokers & Total \\
\hline $108(51.9 \%)$ & $100(48.1 \%)$ & $208(100 \%)$ \\
\hline
\end{tabular}

Study group consisted of 208 subjects, of which 108 (51.9\%) subjects were smokers including all forms of tobacco use and $100(48.1 \%)$ subjects were non smokers as a control group. 
Table 2: Mean age in the study group

\begin{tabular}{lllll}
\hline Variables & Total & $\begin{array}{l}\text { Mean } \\
\text { (years) }\end{array}$ & age & P value \\
\hline $\begin{array}{l}\text { Smokers } \\
\text { Non smok- }\end{array}$ & 108 & 53.52 & $\mathrm{P}<0.05$ \\
ers & 100 & 59.48 & \\
\hline
\end{tabular}

Mean age in the smokers group was 53.52 years and Mean age in the non smokers group was 59.48 years. Statistically significant $(\mathrm{p}<0.05)$ difference was seen in the mean age between smokers and non smokers who presented with first episode of Acute coronary syndrome. The smokers presented with acute coronary syndrome approximately 7 years earlier than non smokers.

\begin{tabular}{|llll|}
\hline \multicolumn{4}{|c|}{ Table 3: Sex distribution of the study subjects } \\
\hline Variables & Smokers & $\begin{array}{l}\text { Non smok- } \\
\text { ers }\end{array}$ & P value \\
Males & $80(74.1 \%)$ & $39(39 \%)$ & - \\
Females & $28(25.9 \%)$ & $61(61 \%)$ & - \\
Total & $108(100 \%)$ & $100(100 \%)$ & $\mathrm{P}<0.001$ \\
\hline
\end{tabular}

Out of 108 study subjects in the smokers, 80 (74.1\%) were males and $28(25.9 \%)$ were females. Out of 100 study subjects in the non smokers, 61 (61\%) were females and 39 (39\%) were males.

In the smokers group, Acute coronary syndrome was more frequently encountered in males $(74.1 \%$ versus $39 \%, \mathrm{p}<0.001$ )where as in the non smokers group, Acute coronary syndrome was often encountered in females $(61 \%$ versus $28 \%$ ).

\section{Distribution of Risk Factors in the study subjects}

Table 4: Prevalence of Diabetes mellitus in the study subjects.

\begin{tabular}{llll}
\hline *DM & Smokers & $\begin{array}{l}\text { Non smok- } \\
\text { ers }\end{array}$ & P value \\
\hline Absent & $82(76 \%)$ & $56(56 \%)$ & $<0.005$ \\
Present & $26(24 \%)$ & $44(44 \%)$ & \\
Total & $108(100 \%)$ & $100(100 \%)$ & \\
\hline
\end{tabular}

*DM: Diabetes mellitus

Out of 108 study subjects in the smokers, Diabetes mellitus was present in 26 (24\%) subjects. Out of 100 study subjects in the non smokers, Diabetes mellitus was present in $44(44 \%)$ subjects.

Diabetes mellitus was less commonly encountered in the smokers group $(24 \%$ versus $44 \%, \mathrm{p}<0.005$, statistically significant) when compared to the non smokers group.

\begin{tabular}{llll}
\hline \multicolumn{4}{|c|}{ Table 5: Prevalence of Hypertension in the study subjects: } \\
\hline *HTN & Smokers & $\begin{array}{l}\text { Non smok- } \\
\text { ers }\end{array}$ & P value \\
Present & $56(51.9 \%)$ & $60(60 \%)$ & - \\
Absent & $52(48.1 \%)$ & $40(40 \%)$ & - \\
Total & $108(100 \%)$ & $100(100 \%)$ & $\begin{array}{l}0.167 \\
(* * \mathrm{NS})\end{array}$ \\
\hline
\end{tabular}

*HTN: Hypertension, **NS: Non significant

Out of 108 study subjects in the smokers, Hypertension was present in $56(51.9 \%)$ subjects. Out of 100 study subjects in the non smokers, Hypertension was present in $60(60 \%)$ subjects.

Hypertension was commonly encountered in both study groups $(51.9 \%$ versus $60 \%, \mathrm{p}>0.05$, statiatically non significant).

Table 6: Prevalence of Overweight/Obesity in the study subjects

\begin{tabular}{llll}
\hline Overweight/C Smokers & $\begin{array}{l}\text { Non smok- } \\
\text { ers }\end{array}$ & P value \\
\hline Absent & $34(31.5 \%)$ & $67(67 \%)$ & - \\
Present & $74(68.5 \%)$ & $33(33 \%)$ & - \\
Total & $108(100 \%)$ & $100(100 \%)$ & $\mathrm{P}<0.001$ \\
\hline
\end{tabular}

Out of 108 study subjects in the smokers group, Overweight/ Obesity was present in 74(68.5\%) subjects. Out of 100 study subjects in the non smokers, Overweight/ Obesity was present in $33(33 \%)$ subjects.

Overweight/Obesity was often encountered in the smokers group ( $68.5 \%$ versus $33 \%, \mathrm{p}<0.001$, statistically significant) when compared to the non smokers group.

Table 7: Prevalence of the family history of Coronary Artery disease in study subjects

\begin{tabular}{llll}
$\begin{array}{l}\text { Family H/o } \\
\text { *CAD }\end{array}$ & Smokers & $\begin{array}{l}\text { Non smok- } \\
\text { ers }\end{array}$ & P value \\
Absent & $87(80.6 \%)$ & $74(74 \%)$ & - \\
Present & $21(19.4 \%)$ & $25(25 \%)$ & - \\
Total & $108(100 \%)$ & $100(100 \%)$ & $0.351(* * N S)$ \\
\hline
\end{tabular}

*CAD: Coronary artery disease; **NS:Non significant.

Out of 108 study subjects in the smokers group, family history of CAD was present in 21(19.4\%) subjects. Out of 100 study subjects in the non smokers group, family history of CAD was present in $25(25 \%)$ subjects.

Family history of CAD was less commonly and equally distributed in both study groups (19.4\% versus $25 \%, \mathrm{p}>0.05$, statiatically non significant). 
Table 8: Prevalence of combined Hypertension and Diabetes mellitus in the study subjects

\begin{tabular}{llll}
\hline$*$ DM+**HTr Smokers & $\begin{array}{l}\text { Non smok- } \\
\text { ers }\end{array}$ & P value \\
Absent & $90(83.3 \%)$ & $77(77 \%)$ & \\
Present & $18(16.7 \%)$ & $23(23 \%)$ & \\
Total & $108(100 \%)$ & $100(100 \%)$ & $\begin{array}{l}0.349 \\
(* * * N S)\end{array}$ \\
\hline
\end{tabular}

*DM (Diabetes mellitus); **HTN(Hypertension); ***NS(Non significant).

Out of 108 study subjects in the smokers group, combined DM and HTN was present in $18(16.7 \%)$ subjects. Out of 100 study subjects in the non smoker group, combined DM and HTN was present in $23(23 \%)$ subjects.

Combined DM and HTN was less commonly and equally distributed in both study groups ( $16.7 \%$ versus $23 \%$, $p>0.05$, statiatically non significant).

Table 9: Prevalence of combined Hypertension and Diabetes mellitus with Overweight/Obesity in the study subjects

\begin{tabular}{llll}
\hline$*$ DM+**HTS Smokers & $\begin{array}{l}\text { Non } \\
\text { smokers }\end{array}$ & P value \\
Absent & $97(89.8 \%)$ & $86(86 \%)$ & - \\
Present & $11(10.2 \%)$ & $14(14 \%)$ & - \\
Total & $108(100 \%)$ & $\begin{array}{l}100 \\
(100 \%)\end{array}$ & $\begin{array}{l}0.398 \\
(* * * N S)\end{array}$ \\
\hline
\end{tabular}

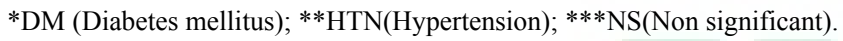

Out of 108 study subjects in the smokers group, combined DM and HTN with Obesity was present in 11(10.2\%) subjects. Out of 100 study subjects in the non smoker group, combined DM and HTN with Obesity was present in $14(14 \%)$ subjects. Combined DM and HTN with Obesity was less commonly and equally distributed in both study groups $(10.2 \%$ versus $14 \%$, $\mathrm{p}>0.05$, statiatically non significant).

Table 10: Diagnosis of Acute coronary syndrome in the study subjects at time of presentation.

\begin{tabular}{|llll|}
\hline Type of ACS & Smokers & Non smokers & P value \\
Acute *MI & $94(87.1 \%)$ & $70(70 \%)$ & $<0.001$ \\
**UA & $14(12.9 \%)$ & $30(30 \%)$ & $<0.001$ \\
\hline Total & $108(100 \%)$ & $100(100 \%)$ & - \\
\hline
\end{tabular}

*MI (Myocardial infarction); **UA (Unstable angina)

Acute myocardial infarction (STEMI+NSTEMI) was the most common presentation in both smokers (87.1\%) and non smokers $(70 \%)$. But Acute myocardial infarction, as the initial presentation, was often encountered in smokers when compared to non smokers ( $87.1 \%$ versus $70 \%, p<0.001$, statistically sig-
nificant).Unstable angina was often encountered as initial presentation in Non smokers when compared to Smokers $(30 \%$ versus $12.9 \%, \mathrm{p}<0.001$, statistically significant).

\section{Discussion}

The present study determines the demographic characteristics and angiographic extent of coronary artery lesions in smokers and non smokers having acute coronary syndrome, with comparative analysis focusing on patients presented with STEMI vs. NSTEMI/UA.

In the present study, the majority of patients in the smoking group were males $(74.1 \%)$ when compared to females but majority of patients in the non smoking group were females (61\%).The mean age of the patients in the smoking group was 53.52years and in the non smokers, mean age was 59.48years. In the present study, smoking reduced the age at which the first coronary event occurred by approximately seven years.

Majority of the study subjects reached ICCU with acute myocardial infarction as acute coronary event but unstable angina with ECG changes was often encountered in the non smokers group. The smokers had a greater prevalence of infarction and less unstable angina, probably related to younger age and due to the procoagulant effect of tobacco.

In smokers, anterior wall STEMI (44.1\%) was the most common presentation followed by acute inferior wall STEMI $(34.3 \%)$.

A stronger association was seen between smoking and obesity and a weaker one with Diabetes mellitus. Diabetes mellitus was more common in the non smoker group. Hypertension had no association with smoking.

Diabetic status had a significant impact on morbidity \& mortality of the patients with ACS in our study. Patients with diabetes and first time detected diabetes had more number of patients in advanced Killip class (Killip class $3-32.3 \%$ and $20.6 \%$ resp.) compared to patients with normal blood sugar $(8.6 \%)$.

Smokers had a relatively greater number of associated risk factors than non smokers. The smokers had more obesity than non smokers.

Majority of the patients (74.1\%) in the study group had EF $>50 \%$ with mean EF was $55.56 \%$.

The prevalence of hypertension in our ACS patients was $75 \%$.This is higher as compared with INTERHEART study (31\%). $44 \%$ were diabetics .It is higher as compared to INTERHEART, however near to other Indian \studies. ${ }^{[7,8]}$ By 2025, the number of diabetics in India is projected to surpass 57.2 million. Diabetics have endothelial dysfunction, dyslipidemia, chronic inflammatory state which is responsible 
for increased atherosclerosis. Smoking was present as risk factor in $65 \%$ of the cohort.

Smoking was also most common modifiable risk factor in INTERHEART. BMI more than 30 was seen in $6.5 \%$ of patients which is less as compared with INTERHEART (44\%), which may be due to different criteria used in INTERHEART( waist hip ratio). Dyslipidemia was present in $60 \%$ of the cohort, however no significant relationship could be found between levels of various lipid parameters and CAD severity on angiography. Single-vessel disease was most prevalent across all ACS group followed by double-vessel and triple vessel which is similar to other studies. ${ }^{[9,10]}$

\section{Conclusion}

Larger studies will be required to establish specific associations between presentation of acute coronary syndromes and angiographic profiles in young patients. We strongly believe that such information may be of significant value for the prevention and management of cardiovascular disorders considering that acute coronary syndrome itself is an uncommon occurrence in younger patients. Overall, we encourage the recommendation of healthy lifestyles, particularly avoidance of smoking/tobacco consumption. STEMI was most common presentation. LAD was most commonly involved vessel. Males predominated in our ACS population. Hypertension and Smoking were most prevalent risk factors. Diabetics had more aggressive disease with higher morbidity and mortality as compared to non diabetics.

\section{Acknowledgment}

The author thankful to Department of cardiology, Katuri Medical College \& Hospital for providing all the facilities to carry out this work.

\section{References}

1. Badran HM, Elnoamany MF, Khalil TS, Eldin MME. AgeRelated Alteration of Risk Profile, Inflammatory Response, and Angiographic Findings in Patients with Acute Coronary Syndrome. Clin Med Cardiol. 2009;3:15-28. Available from: https://dx.doi.org/10.4137/cmc.s2118.

2. Gaziano TA, Bitton A, Anand S, Abrahams-Gessel S, Murphy A. Growing Epidemic of Coronary Heart Disease in Low- and Middle-Income Countries. Curr Problems Cardiol. 2010;35(2):72-115. Available from: https://dx.doi.org/10. 1016/j.cpcardiol.2009.10.002.

3. Zaman MJS, Philipson P, Chen R, Farag A, Shipley M, Marmot $\mathrm{MG}$, et al. South Asians and coronary disease: is there discordance between effects on incidence and prognosis? Heart. 2013;99(10):729-736. Available from: https://dx.doi.org/10. 1136/heartjnl-2012-302925.

4. Sharma M, Ganguly NK. Premature coronary artery disease in Indians and its associated risk factors. Vasc Health Risk Manag. 2005;1:217-242.

5. Kaul U, Bhatia V. Perspective on coronary interventions \& cardiac surgeries in India. Indian J Med Res. 2010;132:543551.

6. Prajapati J, Joshi H, Sahoo S. Age-related differences of novel atherosclerotic risk factors and angiographic profile among gujarati acute coronary syndrome patients. J Clin Diagn Res. 2015;9:5-9.

7. Yildirim N, Arat N, Doğan MS. Comparison oftraditional risk factors, natural history and angiographicfindings between coronary heart disease patients withage $<40$ and $>$ or $=40$ years old. Anadolu Kardiyol Derg. 2007;7:124-131.

8. Jose VJ, Gupta SN. Mortality and morbidity of acute STsegment elevation myocardial infarction in the current era. Indian Heart J. 2004;56:210-224.

9. Xavier D, Pais P, Devereaux PJ, Xie C, Prabhakaran D, Reddy KS, et al. Treatment and outcomes of acute coronary syndromes in India (CREATE): a prospective analysis of registry data. Lancet. 2008;371(9622):1435-1442. Available from: https: //dx.doi.org/10.1016/s0140-6736(08)60623-6.

10. Tewari S, Kumar S, Kapoor A, Singh U, Agarwal A, Bharti BB. Premature coronary artery disease in North India:An angiography study of 1971 patients. Indian Heart. 2005;57:311-319.

Copyright: (C) the author(s), 2020. It is an open-access article distributed under the terms of the Creative Commons Attribution License (CC BY 4.0), which permits authors to retain ownership of the copyright for their content, and allow anyone to download, reuse, reprint, modify, distribute and/or copy the content as long as the original authors and source are cited.

How to cite this article: Reddy BVN, Korrapati H, Chegireddy S. A Study on Clinical Profile, Risk Factors, Angiographic Profile and Short-Term Mortality of Acute Coronary Syndrome in Smokers vs Non Smokers. Asian J. Med. Res. 2020;9(2):1-5.

DOI: dx.doi.org/10.47009/ajmr.2020.9.2.ME1

Source of Support: Nil, Conflict of Interest: None declared. 